\title{
Management of Super-Obese Pregnancy - A Successful Outcome
}

\author{
AMENA BEGUM ${ }^{1}$, ABDULLAH AL MARUF ${ }^{2}$, S.M. SHAHIDA ${ }^{3}$
}

\begin{abstract}
:
Pregnancy associated with obesity is a challenge ${ }^{1}$. When surgical delivery is indicated that present a unique challenge ${ }^{2}$.A case of pregnancy with morbid obesity with a successful outcome is presented here.
\end{abstract}

\section{Introduction:}

Pregnancy associated with obesity is a challenge. ${ }^{1,2}$ Obesity can be defined as $\mathrm{BMl}>30 \mathrm{~kg} /$ $\mathrm{m}^{2}$ and further categorized as class-l: BMI $30-34.9 \mathrm{~kg} /$ $\mathrm{m}^{2}$ class-II: BMI $35-39.9 \mathrm{~kg} / \mathrm{m}^{2}$; class-III:BMI> 40kg/ $\mathrm{m}^{2}$. Other term used include severe (morbid) obesity for those with BMI>40 kg/m $\mathrm{m}^{2}$ and super (super morbid)obesity for $\mathrm{BMI}>50 \mathrm{~kg} / \mathrm{m}^{2}{ }^{2}$ The percentages of women with a body mass index (BMI) of $50 \mathrm{~kg} / \mathrm{m} 2$ or more than increase five fold in 20 years. ${ }^{3}$ Today more than $35 \%$ of population is obeseand obstetricians encounter the problem with increasing frequency. ${ }^{4}$ Obesity has a dramatic impact on pregnancy outcome. Apart from an associated increased prevalence of DM, HTN, PIH, Obese mother have an increased risk of pregnancy complication, such as anaemia, GDM, PE, primary $\mathrm{PPH}$, and most dreadful wound complication. Anesthesia related complications are also frequent in these cases. Moreover obese pregnancy has been associated with poor perinatal and neonatal outcome. Neonatal consequences of obesity include an increase rate of stillbirth and macrosomia. ${ }^{2,4}$ Shoulder dystociais also common.Obese woman have an increased rate of cesarean delivery and related complications. So a holistic approach involving a team ofphysician and nurse from relevant disciplines is required to provide an ideal and successful outcome management.

\section{Case:}

A 30 years old lady, gravida $2^{\text {nd }}$ para -1 with history of caesarian sectionwas referred to tertiary level hospital, at her 34 weeks of gestation with morbid obesity. Her pregnancy was planned and conceived without any medical assistance. She was a booked case with regular antenatal check up. She gave history of adolescence obesity and her pre pregnancy weight was $120 \mathrm{~kg}$. She was normotensive, nondiabetic and there was no endocrine disease. On examination her height was 1.67 meter; weight-143 kg. $\mathrm{BMI}=51.27 \mathrm{~kg} / \mathrm{m}^{2}$. General condition was fair. All other systems were found normal.

On per abdomen examination, abdominal circumference was $110 \mathrm{~cm}$ at 34 at weeks. Fundal height couldn't be delineated. Presentation couldn't be felt and fetal heart beat was localized by Doppler. On laboratory examination, all hematological and biochemical parameter were within normal limit including tolerance test.TSH; and oral glucose.As the patient had previous Caesarian section, she was planned for elective Caesarian section at her 38 weeks of gestation.

Accordingly, she was admitted. She was again screened for hemoglobin; Blood Sugar,coagulation profile,liver function test and urine analysis. On admission her weight was $150 \mathrm{~kg}$, So, BMI $53.78 \mathrm{~kg} /$ $\mathrm{m}^{2}$. $\mathrm{Hb}$ percentage was $12.1 \mathrm{gm} / \mathrm{dl}$. Pre anestheticcheck up was done. She was placed ASA grade IV and planned for combined spinal epidural anesthesia. Informed written consent was taken after providing detailed information on per operative and post operative probable complications, to the patient and her attendant. Neonatologist was informed and the donor kept standby. Three expert assistant was called to attend the case. PPH kit was confirmed prior to operation.

1. Lt Col Amena Begum, Gynaecologist, Border Guard Hospital, Dhaka

2. Col Abdullah AI Maruf, Aneaestheiologist, Border Guard Hospital, Dhaka

3. Dr. S.M. Shahida, Asst. Professor, Dhaka Medical College

Address of correspondence: Lt Col Amena Begum, Gynaecologist, Border Guard Hospital, Dhaka, Mobile: 01713332059 , E-mail: amena_lipi@yahoo.com 
On day of operation, anesthesia was given with great difficulty. Patient received prophylactic anti-biotic prior to incision.Pfannenstiel incision was planned. Two assistant retracted the panniculus. Luckily, adhesion was very minimum. A female baby of 3.1 $\mathrm{kg}$ weight with APGAR score $8 / 10$ was delivered. After ensuringhaemostasis wound was closed in layered including three layers on the subcutaneous tissue. The skin was closed with 2,0prolene with subcuticular suture.

Total operation time was 75 min.Postoperatively patient was nursed in ICU for first 24 hours with the following medication, prophylactic antibiotic inj. Ceftriaxon- 2 gm/i/v/ 12 hourly; inj. Metronidazol$500 \mathrm{mg} / \mathrm{l} / \mathrm{v}$ 8hourly; adequate analgesic by epidural catheter with $0.5 \%$ bupivacain $4 \mathrm{ml}+$ distilled water $4 \mathrm{ml}$ 14 hourly and catheterization for 24 hrs.After 6 hrs she was allowed for oral diet in the form of liquid followed by solid diet. All through patient was encouraged for early ambulation. She was actively ambulating and shift to post operative ward after 48 hours. All injectable form was change to oral form and dressing also change on $3^{\text {rd }}$ post operative day. On $10^{\text {th }}$ postoperative day dressing was removed, suture material cut off, wound was healthy. She was discharged from hospital on that day with the counseling and advice for weight reduction in addition to the regular post natal counselling. During discharge her $\mathrm{Hb} \%$ was $11.1 \mathrm{gm} / \mathrm{dl}$.

\section{Discussion:}

Obesity especially obesity in pregnancy is a curse of modern day lifestyle, which has far reaching effects beyondthe present pregnancy into the next generation, in the form of childhood and adult obesity ${ }^{5}$ and metabolic diseases.

Super obese women are at significantly increased risk of pregnancy complication, even compared to other obese and morbidly obese women. These include gestational hypertension, (7.7); Pre-Eclamsia (11.5\%); Gestational Diabetis Mallitus (15.4\%); Caesariansection (50\%); macrosomia (42.3\%); Repeated Pregnancy Loss; Shoulder dystocia ; Post PartumHemorrhage,Anemia. ${ }^{6}$

Weiss et al. demonstrated that obesity significantly increases the rate of Caesarian section, in normal weight $20.75,33.8 \%$ in obese and $47.4 \%$ in morbid obese. ${ }^{7}$

Obese women have twice the rate of primary caesarian section, emergency caesarian section, primary PPH, and most feared wound complication.
Wound complication have been reported to occur after $2.5 \%$ to $16 \%$ of caesarian section in women of normal BMI but many occur in up to $30 \%$ of those who are obese. ${ }^{8}$

The incidenceof primary PPH varies from zero to a $70 \%$ in morbidly obese women.Blood loss is always difficult to quantify and a more useful outcome could be given by packed cell transfusion. ${ }^{9}$ As such to combat primary post partumhemorrhage $\mathrm{PPH}$ kithas to be kept ready, donar kept standby, which has been done out patient.

Obesity and caesarian section both are risk factor for thromboembolic manifestation. Thoughthromboembolic manifestation is double in obese case, scientific evidence is lacking to answer this question whetherpre or post operativeprophylaxis isto be used to cover the risk of thromboembolism. Most recommendation is based on expert opinion.According to RCOG protocol:

- Woman with a BMI more than 30 who also has two or more additional risk factors for thromboembolism should be considered for prophylactic low molecular weight heparin (LMWH) antenatally.

- Women receiving LMWH antenatally should usually continue prophylactic dose until six weeks post partum. ${ }^{2}$

- Early ambulation should be encouraged, if there is no contraindication. Mechanical thrombo prophylaxis, such as pneumatic compression stocking can be used. Though BMI of our patient was $>50$ associated with history of Caesarian section she did not receive any low molecular weight heparin ( $\mathrm{LMWH}$ ) antenatally and postnatally.

Post operative wound infection is found double with every five unit increment of BMI. ${ }^{9}$ Post operative hospital stay is also longer in obese than normal weight patient. Post operative wound infection, wound dehiscence, wound disruption; UTI can be encounter by proper asepsis, per operative tissue handling, appropriate suture material, subcutaneous tissue closure, and most importantly prophylactic antibiotic. Standard dose of antibiotic are less likely to achieve therapeutic tissue level in obese patient, so in an obese patient $2 \mathrm{gm}$ of third generation cephalosporin is recommended rather than $1 \mathrm{gm} .{ }^{9}$ which was applied in our case. 
Though most of caesarian section does not require pre-anestheticcheck up but morbid obese pregnancy need pre anestheticevaluation and a scheduled Caesarian section is standard.Our case had dual risk; history of cesareain section and super morbid obesity. So, pre-anesthetic check up was done. Low transverse skin incision and transverse uterine incision are definitely superior and must be the first option. Closure of the subcutaneous layer is recommended but placement of subcutaneous drain remains controversial. In our case no drain was given and subcutaneous fat was closed in three layers. A meta-analysis according to Alanis MC et.el. demonstrated that subcutaneous tissue closure in women with fat thickness more than $2 \mathrm{~cm}$ reduced wound disruption by $34 \% .{ }^{9}$ Overall, patient with BMI more than $40 \mathrm{~kg} / \mathrm{m}^{2}$ have an increase in total operative time and time from skin incision to delivery. ${ }^{9}$

Physician should be aware regarding dealing with the morbid obese patient in respect of logistic nursing stuff, obstetrician, anesthetist and pediatrician. Nursing care of obese patient requiresargonomic adaptation, and knowledge about the special cousion involved in caring for this patient. Competant nurses are necessary for caring the morbidly obese patient. ${ }^{10}$

Weight reduction inpost partum period and thereafter must be strongly encouraged for optimal future pregnancy outcome and well being.

Timely referral to a tertiary centre is necessary in order to ensure optimum management facilities to the patient to reach a successful outcome.

\section{References:}

1. Joshi AV, Mhaske NC,Barhate SK.Pregnancy with super-obesity: an emerging pandemic."Joshi AV et al. Int J Reprod Contracept Obstet Gynecol. 2016 Jan:5(1):255-257.

2. Mariona FG,Plymel KL. "Use of the ' 0 ' Wound Protector/Retractor in Extremely Obese
Pregnant Woman- An Unexpected Event." J Women's Healthcare 2015, 4:4.

3. Ng M, Fleming $T$, Robinson $M$, Thomson B, GraetzN, Margono C, et al. Global, regional, and nationalprevalence of overweight and obesity in children andadults during 1980-2013: a systematic analysis forthe Global Burden of Disease Study 2013. Lancet Elsevier. 2014;28;384(9945):766-81.

4. Cedergren Ml; Maternal morbid obesity and risk of advance pregnancy outcome. Obstetgynecol, 2004; 103 (2): 219-224.

5. Machado LSM. "Cesarean Section in Morbidly obese Parturients: Practical Implications and Complications." N Am J Med Sci. 2012 Jan; 4(1):13-18.

6. Grossetti E, Beucher G, Régeasse A, LamendourN, Herlicoviez M, Dreyfus M. Obstetrical complications of morbid obesity. J Gynecol Obstet Biol Reprod (Paris). 2004;3 3(8):739-44

7. Weiss JL, Malone FD, Emig D, Ball RH, Nyberg DA, Comstock $\mathrm{CH}$, et al. FASTER Research consortium. Obesity, obstetric complications and cesarean delivery rate-a population based screening study.AM J Obstet Gynecol. 2004;190:1091-7.

8. Lynch CM, Sexton DJ, Hession M, Morrison JJ.Obesity and mode of delivery in primigravid and

9. Alanis MC, Villers MS, Law TL. Complications of Cesarean delivery in the massively obese parturient. AM J Obstet Gynecol. 2010;203:271.

10. Vallejo MC. Anesthetic management of the morbidly obeseparturient. CurrOpinAnaesthesiol. 2007; 20(3):175-80. 